\title{
NATURE: THE BEST SOURCE FOR CANCER TREATMENT-A REVIEW
}

\author{
Shalini K. Sawhneya*\& Monika Singha \\ alTS College of Pharmacy, Muradnagar, Ghaziabad-201206, U.P. India
}

(Received on Date: 24 ${ }^{\text {th }}$ April 2020

Date of Revision\& Acceptance: $4^{\text {th July }} 2020$

Date of Publish: 1st September 2020)

Email : shaliniksawhney@its.edu.in

\begin{abstract}
Background-Cancer is one of the primary diseases that causes morbidity and death in millions of persons globally and because of its existance, there is indeed an unmet need to realize and discover novel anticancer drugs. The traditional procedure of drug discovery \& improvement is extensive and costly, therefore systematic and exploration interest is drawing its consideration towards naturally-extracted compounds as they show less toxic side effects as compared to existing treatments like chemotherapy. ObjectivesPlants yields naturally occurring secondary metabolites which are being explored for their anticancer actions leading to the growth of novel clinical drugs. Methods-Searching the technical literature showed that few of these molecules (Neoechinulin, Colchicine, and Piperolactam) have previously been experimentally curtained for their anticancer action and were found active. This review deliberates the claim for naturally-derived compounds from therapeutic plants and their properties which make them the objectives for potential cancer treatment. Results- With improvements and findings in naturally derived drugs new tools are evolving for the claim and dosage of these anticancer compounds. With effective clinical trials drugs being established from plant origins are popular for clinical development. They are found to be safe on normal cells and their cytotoxic effects on cancer cells place them in great demand. Conclusion-Plant-derived anticancer sources are active inhibitors of cancer cells lines, making them in great demand. We need to utilise of these sources needs to keep up with the demands and be sustainable.
\end{abstract}

Keywords: anticancer, secondary metabolites, polyphenols, cytotoxicity, epigenetics, nanoparticles 


\section{INTRODUCTION}

Cancer is a well-recognized global health problem responsible for 7.6 million deaths (13\% of all deaths) worldwide, which is expected to rise to 13.1 million by 2030 . Cancer is one of the major world-wide diseases that cause morbidity and death in millions of persons universally [1]. Liver, lungs, prostate, colorectum and stomach are the 5 most common sites for cancer found in men and amongst women it is the breast, lungs, colorectum, stomach \& cervix [2]. Current cancer therapies involve surgical removal or treating with radiation of the amassed biomass of cancer, followed by chemotherapy treatment for maintenance treatment. The major problem of chemotherapy is the recurrence of cancer, along with drug resistance, and severe side effects which limit the use of anticancer drugs. Still, chemotherapy is used widely for the treatments in all kinds of cancers. There is a need to determine and improve anticancer therapeutic agents. Nature is an abundant home of novel beneficial compounds as a remarkable chemical diversity is found in lots of classes of plants, animals, marine organisms and microorganisms as possible agents for cancer treatment. It has been observed that natural products are the rich source of high chemical diversity, which provides the basis for credentials of novel structures serving as the starting material for rational drug design.

The molecular origin of cancer cell improvement has been credited to two main components, which are oncogenes and tumor suppressor genes [3, 4]. The inactivation of tumor suppressor genes can result in uncontrolled cell growth [5]. To understand the molecular mechanisms of cancer progression has resulted in the expansion of a large number of anticancer drugs; Therefore, the innovation and growth of new drugs based on natural products have been the focus of much exploration [6, 7]. Flavonoids, alkaloids, polysaccharides, terpenoids and saponins have been recognised as natural bioactives with strong anticancer activity [8-10]. The drug discovery based on plant source gave rise to the growth of many anticancer agents which includes plants etoposide, camptothecin, topotecan, irinotecan, paclitaxel, vincristine and vinblastine, marine organisms includes citarabine, aplidine and dolastatin 10 and microorganisms includes dactinomycin, bleomycin and doxorubicin. There are also several agents recognised from vegetables \& fruits which have shown anticancer activity. Several anticancer agents which are in experimental use and have shown substantial usefulness against cancer initiate from products derived from marine organisms, microorganisms and plants [11]. The anticancer activity of many natural products mainly act through variable immune function, bringing apoptosis or autophagy, or preventing cell proliferation.

Mother Nature is the good source of drugs[12, 13] and because of our attention towards identifying novel anticancer natural products which overcome the limits of cell toxicity and adverse effects, besides improvements in efficiency, we have in silico model for identifying natural products for their bioactivity. Structural based [14-16] and/or Ligand-based techniques [17, 18] are mainly used for making analytical models and for the in silico screening of large chemical databases, which detects novel bioactive ligands [19, 20]. Models for splitting active from inactive ligands can be established by choosing sets of active and inactive chemicals and using certain optimization methods (such as 
neural networks [21], genetic algorithms [21], support vector machines [22], the knearest neighbor algorithm, [23, 24], or of some combination [25-27]). We must know the sets of active/ inactive ligands to get more substantial and vigorous conclusions .

The iterative stochastic elimination (ISE) optimization method is a current improvement that is seen in recent research publications $[16,17,19,27,28]$. It is a technique to search for a multidimensional planetary so that we can recognise the best solutions (termed global minima and local minima). ISE has been used to position proton in proteins [29], the side-chain conformations estimation [30], loop conformations verification[31], and the conformational space of cyclic peptides [32]. ISE has also been used to solve several problems regarding chemoinformatics [19]; The filters created are used to index the bioactivity of ligands and to rank and prioritize molecules in huge chemical databases [17, 28, 33, 34].

In this review article, we look forward for a novel model for indexing natural products for their activity against cancer, and record the discriminative physicochemical properties of 617 FDAapproved anticancer drugs concluded through analysis of the configuration of filters that were produced by ISE for indexing purposes.

\section{EPIGENETIC PROPERTIES}

The step towards development of cancer involves alterations of epigenetic processes and their deregulation. The control of hypermethylation of tumoursuppressor genes on CpG islands is deregulated in cancer cells. This can result in gene silencing and inactivation of tumour-suppressor genes [35].

Chemically derived epigenetic drugs have been developed and undergone trials such as 5-azacytidine (azacitidine; Vidaza) and 5-aza-2'-deoxycytidine (decitbine; Dacogen) which are both
DNMTi and HDACi such as suberoyanilde hydroxamic acid (SAHA, Vorinostat, Zolinza) and FK228 (Romidespin, Istodax) . As it is tough to make a chemically derived drug which is not toxic to common cells and is also explicit to cytotoxicity of cancer cells. Subsiquently development and research of naturally derived compounds to be used as anticancer is in demand. Apoptosis is avoided and not encouraged in cancer cells and angiogenesis is continued within the tumour tissue permitting survival of cancer cells. Plant derived compounds have shown properties to kill cancer cell activity such as inhibiting proliferation of cancer cells and inducing apoptotic cell death.

\section{ANTICANCER PROPERTIES OF PLANT COMPOUNDS}

Some countrys rely on plant-based treatment as their main source of medicine according to the World Health Organisation (WHO) and developing nations are exploiting the benefits of naturally occuring compounds for beneficial purposes. Recognized and extracted compounds from terrestrial plants for their anticancer properties include polyphenols, brassinosteroids and taxols.

\section{Polyphenols}

Polyphenolic compounds contain flavonoids, tannins, curcumin, resveratrol and gallacatechins are all measured to be compounds against cancer. Resveratrol is found in foods like grapes, red wine and peanuts. Green tea contains Gallactechin. Polyphenols acts as a natural antioxidant and improves health and decreases the risk of cancers [36].

Polyphenols show anticancer properties which can be utilized[37]. Polyphenols carry out apoptosis origination by adaptable mobilization of copper ions which are inevitable to chromatin 
inducing DNA fragmentation. Resveratrol degrade DNA in the presence of $\mathrm{CU}(\mathrm{II})$. Polyphenols also interfere with proteins existing in cancer cells and promote their growth. Cancer agents may get altered through polyphenol changeable acetylation, phosphorylation or methylation through straight bonding. For example, cancer cells treated with curcumin have shown decrease in the Tumour Necrosis Factor (TNF) [38].

\section{Flavonoids}

Flavonoids are polyphenolic compounds and consists of plant secondary metabolites with 10,000 known structures. They are agents which are physiologically active in plants and are of high concern scientifically because of their health benefits.[39].

Several plants have been studied for its flavonoid content and how these compounds affect cancer cells, such as fern species and plants used in traditional Chinese medicines like the litchi leaf. There is a high amount of flavonoid compounds such as flavones, anthocyanins, chalcones, flavonols and many more which are found in just one part of the plant eg its seed [40]. The anticancer effects of flavonoids on human lung cancer cells (A456 cell line) from the fern species Dryopteris erythrosora. was identified by Coa et al., 2013. They found that flavonoids show cytotoxicity on cancer cells and to have great free radical scavenging activity. Purified flavonoids have also shown anticancer activities against other human cancers including; cervical carcinoma (Hela), breast cancer (MCF-7) and hepatoma (Hep-G2). The flavonoids extracted from Erythrina suberosa stem bark (4'-Methoxy licoflavanone (MLF) and Alpinumi soflavone (AIF)) were shown to have cytotoxic effects in HL-60 cells (human leukaemia). MLF and AIF induced apoptosis towards intrinsic and extrinsic signalling pathways. The mitochondrial membrane potential is remarkably reduced because of the induction of apoptotic proteins. The cancer cells cannot survive with mitochondria damage to cells.

As told before polyphenols can obstruct or change the regulation of proteins and other agents which may be helping in the survival of cancer cells. Signal Transducer and Activator of Transcription (STAT) proteins are anti-apoptotic and add to cancer cell growth. MLF and AIF obstruct members of this family of proteins by preventing their phosphorylation needed for the cancer cells life. These flavonoids also obstruct the expression of NF-KB which is required for cancer cell existence and angiogenesis and proliferation.

\section{Brassinosteroids}

Brassinosteroids (BRs) are naturally occurring compounds which have shown therapeutic significance against cancer. BRs are found in plants which signals hormone to control growth, cell differentiation, stem elongation and root cells and other roles such as tolerance and resistance against stress and disease. Also, BRs are used to regulate the plant senescence [41]. They are indispensable for plant development and growth.

Two natural BRs which have shown the anticancer properties have been used in investigations with cancerous cells. These are 28-homocastasterone (28-homoCS) and 24-epibrassinolide (24-epiBL) which demonstrated anticancer effects on several cancer cell lines and have shown effects at micromolar concentrations. Cancer cells do not undergo apoptosis naturally and proliferate indefinitely. BRs can induce responses necessary for growth inhibition and induce apoptosis by interacting with the cell cycle. BRs have been used in surveys to give a range of cancer cell lines which include; multiple myeloma RPMI 8226, Tlymphoblastic leukaemia CEM, cervical carcinoma HeLa, osteosarcoma HOS cell lines and lung carcinoma A-549 [42]. Also included are cell lines in prostate 
cancer and breast cancer. Estrogen receptor (ER), human EGFR-2 (HER-2) and epidermal growth factor receptor (EGFR) are some of the important proteins which are targeted in against breast cancer as they are ample in breast cancer cells such as MCF-7, T47D, MDA-MB-231 and MDA-MB-468. In prostate cancer cells (LNCaP and DU-145 cell lines) the androgen receptor (AR) is an important protein which is involved in its development and shares a comparable structure to ER. BRs will bind to receptors of these proteins and obstruct the growth of both hormone sensitive and insensitive cancer cells [43]. BRs also block cell cycle - Action of breast cancer cell lines with 28-homocs and 24-epiBL showed decrease in cyclin proteins involved in $G_{1}$ cell cycle phase. In the cell cycle, at this phase cells will either under repair or enter apoptosis, action with BRs induces apoptosis at this stage. In prostate cancer cell lines, LNCaP and DU-145, the balance of apoptotic proteins which stimulate cell survival and those which encourage programmed cell death changes with BRs treatment. The levels of the Bax pro-apoptotic protein rise after treatment with BRs and anti-apoptotic proteins such as Bcl-2 gets reduced[43]. BRs generate different responses in normal and cancer cells along with their anticancer properties [42]. Anticancer treatment has main specification, which is that the agent should be cell specific to cancer cells and should not be cytotoxic to normal cells.

\section{ANTICANCER PLANT-DERIVED DRUGS}

Plant-derived drugs are required for anticancer action as they are readily available and can be readily given orally as part of patient's dietary intake. Also, they are further accepted and non-toxic to normal human cells. But there are exemptions also, such as cyanogenetic glycosides, saponins, lectins, lignans, and some taxanes. These fall under four classes of drugs which have the following activities; DNA damage preventive drugs or antioxidants, methytransferase inhibitors, mitotic disruptors and histone deacetylases (HDAC) inhibitors [44]. These compounds are discussed by their origins, anticancer activity and their clinical trial development.

Sulphoraphane -Isolated from cruciferous vegetalles Brassica. It induces phase 2 detoxification enzymes, inhibits tumor growth in breast cancers, antiproliferate effects. Clinical trials are going on with oral administration of cruciferous vegetable preparation with sulphoraphane[45-47].

Paclitaxel (Taxol) - It is isolated from Taxane, Taxus brevifolia $L$. It is a microtubule disruptor, blocks mitosis, induces apoptosis, microtubules are polymerized and stabilized, disruption of spindle formation, inhibits translational machinery. It is under Phase I-III clinical trials; early management settings; nonsmall lung cancer, ovarian cancer, breast cancer, Kaposi sarcoma. Research and development in alternate drug administration using nanoparticles, nanoliposomes and naocochealtes [4852].

Epipodophyllotoxin -Its source is Podophyllum peltatum L.; Podophyllotoxin isomer. It has Proapoptotic effects and interferes cell cycle. It is undergoing Lymphomas and testicular cancer trials [51, 53-54].

Vincristine- Its source is Catharanthus roseus G.Don, Vinca alkaloids. It is Antimitotic, microtubule inhibitor and bind to $\beta$-tubulin, microtubule stabilizers or destabilizers, has pro-apoptotic properties and induce cell cycle arrest, has antitumour activity. Used in lymphomas, sarcomas and leukaemias. It is in combination trials and clinical use. [44, 48, 
53-55].

Vinblastine- Its source is Catharanthus roseus G.Don, Vinca alkaloids. It is Antimitotic, microtubule inhibitor and bind to $\beta$-tubulin, microtubule stabilizers or destabilizers, has pro-apoptotic properties and induce cell cycle arrest, has antitumour activity. It is used in testicular cancer, Hodgkins disease and lymphoma. It is in combination trials and clinical use [44, 48, 54-55].

Vinorelbine- Its source is Catharanthus roseus G.Don, Vinca alkaloids. It is Antimitotic, microtubule inhibitor and bind to $\beta$-tubulin, microtubule stabilizers or destabilizers, has pro-apoptotic properties and induce cell cycle arrest, has antitumour activity. It is used for non-small cell lung cancer. It is under single and combination trials, Phase I-III $[44,48,54]$.

Vindesine- Its source is Catharanthus roseus G.Don, Vinca alkaloids. It is Antimitotic, microtubule inhibitor and bind to $\beta$-tubulin, microtubule stabilizers or destabilizers, has pro-apoptotic properties and induce cell cycle arrest, has antitumour activity. It is undergoing clinical trials for acute lymphocytic leukaemia $[44,54]$.

Vinflunine- Its source is Catharanthus roseus G.Don, Vinca alkaloids. It is Antimitotic, microtubule inhibitor and bind to $\beta$-tubulin, microtubule stabilizers or destabilizers, has pro-apoptotic properties and induce cell cycle arrest, has antitumour activity. It is undergoing Clinical trials for solid tumors and under Phase III clinical trials $[44,48,53]$.

Pomiferin- It is an isoflavonoid isolated from Maclura pomifera, Dereeis Malaccensis. It has pro-apoptotic effects, DNA fragmentation, inhibits oxidative damage of DNA, has antioxidant activity, inhibits histone deacetylases and is of cancer cell cytotoxicity. It inhibits growth six human cancer cell lines: ACHN (kidney), $\mathrm{NCl}-\mathrm{H} 23$ (lung), PC-3 (prostate), MDA-MB-231 (breast), LOX-IMVI (Melanoma), HCT-15 (colon) [44, 56].

Epigallacotechin-3-gallate - Its source is catechin; green tea. It acts as an antioxidant, decreases DNA damage from oxidative stress, has anti-proliferative effects, inhibits specific kinases and carcinogenesis induced chemically or by UV. It is undergoing clinical trials in prostate cancer treatment and Phase I clinical study for oral dose administration [44, 57-58].

Combretastatin A-4 phosphate- It is a water-soluble analogue of combretastatin, Combretum caffrum. It is anti-angiogenic, vasuclar shut-down of tumors and tumor necrosis. It is undergoing early trials, clinical and preclinical trials [52-53].

Roscovitine- It is derived from olomucine, Raphanus sativus L. (Brassicaceae). It inhibit cyclin dependent kinases and reduce cell cycle progression. It is undergoing Phase II clinical trials in Europe [52-53].

Flavopiridol- Synthetic flavonoid derivative; rohitukine based structure; Dysoxylum binectariferum Hook.f. (Meliaceae). It has anti-inflammatory, immunomodulatory, tyrosine kinase activity and growth inhibitory effects. It is undergoing Phase I and Phase II clinical trials in solid tumors, lymphomas, leukaemias $[52-53,59]$.

Noscapine- Opium poppy (Papaver somniferum). It has antiproliferative properties, microtubule interfering, inhibits tumour growth and progression. It is undergoing

Phase I and Phase II clinical trials [60-62]. 
Compounds including isothiocyanates, sulforaphane, isoflavones, pomiferin and isoflavones are considered to be HDAC inhibitors. They prevent the activity of carcinogenic proteins. For example, sulforaphane has shown to obstruct important targets in breast cancer proliferation. Reduced expression of ER, EGFR and HER-2 resulted from HDAC inhibition by sulforaphane action in breast cancer cell lines [45]. In cancer cells, epigenetically-silenced genes which are functional for chromatin acetylation gets galvanised by HDAC inhibitors and cancer cells are then able to enter programmed cell death (apoptosis). Plant-derived combinations which show inhibition of HDAC can proliferate chemotherapeutic sensitivity in human cancers [44-45].

Derivatives of vinca alkaloids, vincristine, vinblastine, vinorelbine, vindesine and vinflunine inhibit the dynamics of microtubules by binding to $\beta$-tubulin. Taxanes such as paclitaxel and its analogue docetaxel are also microtubule disruptors. These compounds kill cell cycle phase transitions from metaphase to anaphase causing cell cycle stop and apoptosis. Replication of cancer cells is decreased by paclitaxel as it stabilizes or polymerizes microtubules in the cells. Paclitaxel was one of the first medications to show an enormous effect on cancer treatment and vincristine and vinblastine were two of the initial drugs to be quarantined [63-65].

Groupings of drugs derived from vinca alkaloids, Podiphyllum lignans, Taxus diterpenes and Camptotheca alkaloids in plant extracts increase their anticancer effects and increase their effectiveness as therapeutic agents [54, 64] . Extracts from Artemesia monosperma, Urtica membranaceae and Origanum dayi Post in Solowely et al., 2014 were studies to test their efficacy on a wide range of cancer cell lines from breast, lung, prostate and colon cancers. The study showed the plant extracts with a combination of anticancer compounds could inhibit the activity which was specific to cancer cells and showed no effect on normal human lymphocytes and fibroblasts. This makes plant extracts remarkable as therapeutic agents than those that are chemically derived and cause toxic complications for cancer treatment. The plant extracts induced apoptosis was demonstrated by an amplified sub-G $G_{1}$ phase population of cells with lower DNA content and condensation of chromatin. Also a rise in caspase 3 activation was realised after the treatment of extract which is a main stage in apoptotic cell death [54].

\section{ENHANCING DRUG ADMINISTRATION}

With discoveries and advancements in naturally derived drugs new technologies are evolving for the dosage and application of anticancer compounds. Management of new drugs is important for the drug to be a successful as alternative to current treatments such as chemotherapy. With the use of nanoparticles (NPs), as a delivery system for drugs to reach target sites, is developing very fast. Some compounds which show activities against cancer may be limited in their clinical development because of the need for high dosages. Bromleain, isolated from Aanas comosus showned more effect as an anticancer agent in formulation with NPs than free bromelain [65]. This research established a safe and biocompatible method using bromelain NPs to sustain discharge of the drug at the target site while also protecting the drug. These bromelain loaded polyllactic-co-glycolic acid NPs (BL-PLCG NPs) disclosed to trigger apoptosis of benign cells more so than free bromelain by modifiable expression of pro-apoptotic and anti-apoptotic proteins in 2-stage skin turmorigenesis in mice. Other NPs synthesized have also been studied such as; copper oxide NPs of Acalypha indica and gold NPs of Antigono leptopus powdered extract [66]. These formulations of plant extract 
and NPs showed cytotoxicity against MCF-7 breast cancer cell lines.

Paclitaxel has been through clinical trials and early treatment settings. Research and development is aiming to use NPs to control release of the drug and enhance target specificity by using magnetic mesoporous silica NPs with a gelatine membrane; Paclitaxel can be controlled externally using a magnetic field. This has shown to be effective in growing the drug's ability to decrease growth of tumours and inhibit unwanted effects of other tissue areas as the drug's distribution is controlled [49]. Achievement has also been seen with the drug quercetin using superparamagnetic magnetite NPs against breast cancer (MCF-7) cell lines [67]. This research showed increased activities of the NPs in cytotoxicity of MCF-7 cells as compared to pure or free quercetin. NPs in their use for anticancer treatment show growing interest and promise as a natural alternative to current treatments.

Alternatively, research investigating application using nanolipososmes and nanocochleates demonstrates success in anticancer activities through oral or inhalable intake $[50,60]$. Paclitaxel given orally is very cost effective and compatible with the patient. A formulation of paclitaxel-loaded nanocochleates which can be given orally showed controlled drug release and effective activities against lung, ovarian and breast cancer cell lines. Also, noscapine was narrow in clinical trials due to insoluble properties until derived analogues were established [60]. Jyoti et al., 2015 studied the noscapine analogue 9-bromo-noscapine in formulation with nano strucutured lipid particles. It showed increased apoptosis and cytotoxicity in lung cancer cell lines with improved uptake of drug into cancerous cells of the formulated noscapine analogue as compared to that of free drug.

\section{MEDICINAL PLANT DEMANDS}

Drugs are developed with plant as source are becoming popular for clinical development with effective clinical trials. Their cytotoxic effects on cancer cells and non-toxic effects on normal cells make them in great demand. Many species studied are selected from developing countries like Africa and Asia where herbal therapies are practiced and medicinal plants are relied for primary treatment. The World Health Organisation estimated in 2007 that the plant-derived drugs trade was worth US $\$ 100$ billion. It is presumed to reach US $\$ 5$ trillion by 2050 [35].

There is a large requirement for medicinal plants in developing countries putting a lot of pressure on the plant populations. Many medicinal plants which are cultivated from wild populations for informal trade, there cultivation is not regulated. With deforestation, rapid population growth and increasing urbanisation the protection of medicinal plants is becoming a very important issue [68-69]. With regular increase in demand, high-value medicinal plants are dangered for extinction this continues. Protection of these plants is important. Only specific parts of the plant are used in treatment such as the bark of a tree or bulbs and tubers from bulbous and tuberous plants. Extracting only a segment of these plant damage and reduce survival of these wild plants [68]. In order to escalate the sustainability of these medicinal plants in developing countries, exploitation of all plant parts including the root, stem, bark, and leaf should be included for the treatment. Germplasm conservation is the other method of conservation; other methods include cryopreservation, storing viable seeds; preserving biological material in liquid nitrogen and tissue culture; propagates plants in sterile conditions and can produce mature plants clones 
quickly of rare species. These preservation methods will also allow for industrial utilization in developed countries [69-70]. In developed areas like Europe and some parts of India and China, medicinal plants are being cultivated on a very large scale to keep up with demands for alternative natural drugs [68]. Attention is being drawn towards foods with medicinal uses, these include cruciferous vegetables and fruit berries [46]. Raw by-products from industries could also be utilized to extract anticancer agents from these agents. Like, one of the largest crops grown globally are 'grape seed extract' and grapes (Vitris vinifera) are usually added in ingredients of food products due to its health benefits. Grape stems are a raw by-product of wine making in the winery industry. This high organic load can be acidic to the environment surrounding the winery. But its high polyphenolic content may make it advantageous for anticancer drug development. Grape stem extracts have shown to have antioxidant properties, prevent DNA damage from reactive oxygen species and demonstrated anticarcinogenic potential against an array of cancer cell lines from thyroid cancer, cervical cancer, and many more [71-72].

\section{CONCLUSION}

Cancer is becoming a high profile disease in developed and developing countries. In 2007 the WHO published that in 2005, 7.6 million people died from cancer related diseases with the majority of these people living in low-income countries [73]. In the United States cancer is the cause of 1 in 4 deaths and in 2010 it was estimated there were over 1.5 million new cases of cancer [74]. Cancer Research UK said in 201214.1 million adults were diagnosed with cancer and 8.2 million people were killed by cancer worldwide [75]. Therefore, the demand for a cure and the prevention of cancer is very high.
Current methods such as chemotherapy have their restrictions due to toxic effects on non-targeted tissues. That is why, there is a demand for alternative treatments with naturally-derived anticancer agents with plants being the desired source. The secondary metabolites in the plant kingdom such as polyphenols, flavonoids and brassinosteroids have been planned for their potential use as anticancer agents. They have been shown to possess anticancer activities like antioxidant, inhibition of cancer cell growth, induction of apoptosis, target specificity; cancer cell cytotoxicity [38-39, 42 , 67]. Plant-derived drugs have been developed from positive results in research and have advanced into clinical trials. Drugs derived from vinca alkaloids were some of the first compounds to be exploited and are developing in clinical Phase III trials along with Pacitaxel and other anticancer agents. These compounds are readily available from the natural environment and are relatively non-toxic to normal human cells. Also there are currently developments using new technologies like nanoparticles to be used in administration of anticancer compounds. Their development could be applied to control sustained drug release and helps to create drugs that are tissue specific reducing severe side effects of treatments.

Growing demand for plant-derived drugs is putting pressure on high-value medicinal plants and risking their biodiversity [68]. Urbanization, increasing populations and deforestation are contributing to species endangerment in developing countries. To aid conservation of these species germplasm conservation, cryopreservation, tissue cultures and plant part substitution strategies need to be in place [70]. Plantderived anticancer agents are effective inhibitors of cancer cells lines, making them in high demand. Exploitation of 
these sources needs to be managed to keep up with demands and to be sustainable.

\section{ACKNOWLEDGMENTS}

The author would like to thank the support given by the ITS College of Pharmacy, Muradnagar, Ghaziabad

\section{REFERENCES}

Lozano R, Naghavi M, Foreman K, Lim S, Shibuya K, Aboyans V, et al. Global and regional mortality from 235 causes of death for 20 age groups in 1990 and 2010: a systematic analysis for the Global Burden of Disease Study 2010. Lancet. 2012;380 (9859):2095-128.

Torre LA, Bray F, Siegel RL, Ferlay J, LortetTieulent J, Jemal A. Global cancer statistics, 2012. CA Cancer J Clin. 2015;65(2):87-108.

Levine AJ, Puzio-Kuter AM. The control of the metabolic switch in cancers by oncogenes and tumor suppressor genes. Science. 2010;330(6009):1340-4.

Ngo DC, Ververis K, Tortorella SM, Karagiannis TC. Introduction to the molecular basis of cancer metabolism and the Warburg effect. Mol Biol Rep. 2015;42(4):819-23.

Ward PS, Thompson CB. Metabolic reprogramming: a cancer hallmark even warburg did not anticipate. Cancer Cell. 2012; 21 (3):297-308.

Wright GD. Opportunities for natural products in 21st century antibiotic discovery. Nat Prod Rep. 2017;34(7):694701 .

Yao H, Liu J, Xu S, Zhu Z, Xu J. The structural modification of natural products for novel drug discovery. Expert Opin Drug Discov. 2017; 12(2):121-40.
Avato $P$, Migoni D, Argentieri M, Tava A, Fanizzi FP. Activity of saponins from Medicago species against HeLa and MCF-7 cell lines and their capacity to potentiate cisplatin effect. Anticancer Agents Med Chem. 2017; 17 (11):15081518.

Joshi P, Vishwakarma RA, Bharate SB. Natural alkaloids as P-gp inhibitors for multidrug resistance reversal in cancer. Eur J Med Chem. 2017; 138: 273-92.

Majumder D, Das A, Saha C. Catalase inhibition an anti-cancer property of flavonoids: A kinetic and structural evaluation. Int J Biol Macromol. 2017; 104 (Pt A):929-35.

Seelinger $M$, Popescu R, Giessrigl B, Jarukamjorn K, Unger C, Wallnofer B, et al. Methanol extract of the ethnopharmaceutical remedy Smilax spinosa exhibits anti-neoplastic activity. Int J Oncol. 2012; 41 (3):1164-72.

Frank A, Abu-Lafi S, Adawi A, Schwed JS, Stark H, Rayan A. From medicinal plant extracts to defined chemical compounds targeting the histamine $\mathrm{H} 4$ receptor: Curcuma longa in the treatment of inflammation. Inflamm Res. 2017.

Kacergius T, Abu-Lafi S, Kirkliauskiene A, Gabe V, Adawi A, Rayan $\mathbf{M}$, et al. Inhibitory capacity of Rhus coriaria L. extract and its major component methyl gallate on Streptococcus mutans biofilm formation by optical profilometry: Potential applications for oral health. Mol Med Rep. 2017;16(1):949-56.

Zaid H, Raiyn J, Osman M, Falah $M$, Srouji S, Rayan A. In silico modeling techniques for predicting the tertiary structure of human $\mathrm{H} 4$ receptor. Front Biosci (Landmark Ed). 2016;21:597-619.

Shahaf N, Pappalardo M, Basile L, Guccione S, Rayan A. How to Choose the 
Suitable Template for Homology Modelling of GPCRs: 5-HT7 Receptor as a Test Case. Mol Inform. 2016;35(8-9):41423.

Pappalardo $M$, Rayan $M$, Abu-Lafi $S$, Leonardi ME, Milardi D, Guccione S, et al. Homology-based Modeling of Rhodopsinlike Family Members in the Inactive State: Structural Analysis and Deduction of Tips for Modeling and Optimization. Mol Inform. 2017;36(8).

Cern A, Marcus D, Tropsha A, Barenholz Y, Goldblum A. New drug candidates for liposomal delivery identified by computer modeling of liposomes' remote loading and leakage. J Control Release. 2017;252 :18-27.

\section{Rayan A, Marcus D, Goldblum A.} Predicting oral druglikeness by iterative stochastic elimination. J Chem Inf Model. 2010; 50(3):437-45. Epub 2010/02/23.

Zatsepin M, Mattes A, Rupp S, Finkelmeier D, Basu A, Burger-Kentischer A, et al. Computational Discovery and Experimental Confirmation of TLR9 Receptor Antagonist Leads. J Chem Inf Model. 2016;56 (9):1835-46.

Pappalardo $M$, Shachaf N, Basile L, Milardi D, Zeidan $\mathbf{M}$, Raiyn $\mathrm{J}$, et al. Sequential application of ligand and structure based modeling approaches to index chemicals for their hH4R antagonism. PLoS One. 2014; 9(10):e109340.

\section{Lusci A, Pollastri G, Baldi P. Deep} architectures and deep learning in chemoinformatics: the prediction of aqueous solubility for drug-like molecules. J Chem Inf Model. 2013; 53(7):1563-75. Epub 2013/06/26.

Zaheer-ul H, Uddin R, Yuan H, Petukhov PA, Choudhary MI, Madura JD. Receptorbased modeling and 3D-QSAR for a quantitative production of the butyrylcholinesterase inhibitors based on genetic algorithm. J Chem Inf Model. 2008;48(5):1092-103.

Heikamp K, Bajorath J. Comparison of confirmed inactive and randomly selected compounds as negative training examples in support vector machinebased virtual screening. J Chem Inf Model. 2013;53(7):1595-601. Epub 2013/06/27.

Shen $M$, Beguin $C$, Golbraikh A, Stables JP, Kohn H, Tropsha A. Application of predictive QSAR models to database mining: identification and experimental validation of novel anticonvulsant compounds. J Med Chem. 2004; 47(9):2356-64.

Rayan A, Falah M, Mawasi H, Raiyn N. Assessing drugs for their cardio-toxicity. Letters in Drug Design \& Discovery. 2010;7(6):409-14.

Deeb O, Jawabreh S, Goodarzi $M$. Exploring QSARs of vascular endothelial growth factor receptor-2 (VEGFR-2) tyrosine kinase inhibitors by MLR, PLS and PC-ANN. Curr Pharm Des. 2013; 19(12):2237-44. Epub 2012/09/29.

Mussa HY, Hawizy L, Nigsch F, Glen RC. Classifying large chemical data sets: using a regularized potential function method. J Chem Inf Model. 2011;51(1):414. Epub 2010/12/16.

Rayan A, Falah M, Raiyn J, Da'adoosh B, Kadan S, Zaid H, et al. Indexing molecules for their hERG liability. Eur J Med Chem. 2013;65:304-14.

Aswad M, Rayan M, Abu-Lafi S, Falah M, Raiyn J, Abdallah $\mathbf{Z}$, et al. Nature is the best source of anti-inflammatory drugs: indexing natural products for their antiinflammatory bioactivity. Inflamm Res. 2017. 
Glick M, Goldblum A. A novel energybased stochastic method for positioning polar protons in protein structures from $\mathrm{X}$ rays. Proteins. 2000; 38(3):273-87. Epub 2000/03/14.

Glick M, Rayan A, Goldblum A. A stochastic algorithm for global optimization and for best populations: a test case of side chains in proteins. Proc Natl Acad Sci U S A. 2002; 99(2):703-8. Epub 2002/01/17.

Michaeli A, Rayan A. Modeling Ensembles of Loop Conformations by Iterative Stochastic Elimination. Letters in Drug Design \& Discovery. 2016;13(3):1-6.

Rayan A, Senderowitz H, Goldblum A. Exploring the conformational space of cyclic peptides by a stochastic search method. J Mol Graph Model. 2004; 22(5):319-33.

Zeidan $M$, Rayan $M$, Zeidan $N$, Falah $M$, Rayan A. Indexing Natural Products for Their Potential Anti-Diabetic Activity: Filtering and Mapping Discriminative Physicochemical Properties. Molecules. 2017;22(9).

M. Greenwell and P.K.S.M. Rahman* Medicinal Plants: Their Use in Anticancer Treatment Int J Pharm Sci Res. 2015 Oct $1 ; 6(10): 4103-4112$

Azmi AS, Bhat SH, Hanif S, Hadi SM. Plant polyphenols mobilize endogenous copper in human peripheral lymphocytes leading to oxidative DNA breakage: A putative mechanism for anticancer Properties. FEBS Letters. 2006; 580: 533538.

Siriwantanmetanon N, Fiebich BL, Efferth T, Prieto JM, Heinrich M. Traditionally used Thai medicinal plants: In vitro anti- inflammatory, anticancer and antioxidant activities. Journal of Ethnopharmacology. 2010;130:197-207.

\section{Gupta SC, Tyagi AK, Deshmukh-Taskar P,} Hinojosa M, Prasad S, Aggarwal BB. Down regulation of tumor necrosis factor and other proinflammatory biomarkers by polyphenols. Archives of Biochemistry and Biophysics. 2014;559:91-99.

\section{Cao J, Xia X, Chen X, Xiao J, Wang Q.} Characterization of flavonoids from Dryopteris erythrosora and evaluation of their antioxidant, anticancer and acetylcholinesterase inhibition activities. Food and Chemical Toxicology. 2013;51:242-250.

Wen $L$, Wu $D$, Jiang $Y$, Prasad $K N$, Lin $S$, Jiang $G$, He J, Zhao $M$, Luo $W$, Yang $B$. Identification of flavonoids in litchi (Litchi chinensis Soon.) leaf and evaluation of anticancer activities. Journal of Functional Foods. 2014;6: 555-563.

Bishop GJ, Koncz C. Brassionsteroids and Plant Steroid Hormone Signaling. The Plant Cell. 2002;(supplement 2002):97110.

\section{Malíková J, Swaczynová J, Koláŕ Z, Strnad}

M. Anticancer and antiproliferative activity of natural brasinosteroids. Phtyochemistry. 2008;69: 418-426.

Steigerová J, Rárová L, Oklešt'ková J, Kř́ižzová $K$, Levková $M$, Šváchová $M$, Kolář Z, Strnad M. Mechanisms of natural brassinosteroid-induced apoptosis of prostate cancer cells. Food and Chemical Toxicology. 2012;50:4068-4076. 
Amin A, Gali-Muhtasib $H$, Ocker $M$, Schneider-Stock R. Overview of Major Classes of Plant-Derived Anticancer Drugs. International Journal of Biomedical Science. 2009;5(1):1-11.

\section{Pledgie-Tracy A, Sobolewski MD,}

Davidson NE. Sulforaphane induces cell type-specific apoptosis in human breast cancer cell lines. Molecular Cancer Therapeutics. 2007;6 (3):1013-1021.

Cornblatt BS, Ye L, Dinkova-Kostova AT, Erb $M$, Fahey JW, Singh $K$, Chen MA, Stierer T, Garrett-Mayer E, Argani P, Davidson NE, Talalay $P$, Kensler TW, Visvanathan K. Preclinical and clinical evaluation of sulforaphane for chemoprevention in the breast. Carcinogenesis. 2007; 28 (7): 1485-1490.

Heiss E, Herhaus C, Klimo K, Bartsch H, Gerhäuser C. Nuclear Factor $K B$ is a Molecular Target for Sulforaphanemediated Anti-inflammatory Mechanisms. The Journal of Biological Chemistry. $2001 ; 276(34): 32008-32015$.

Jordan MA, Wilson L. Microtubules as a target for anticancer drugs. Nature Reviews: Cancer. 2004;4:253-266.

Che E, Gao Y, Wan L, zhang Y, Han N, Bai J, Li J, Sha Z, Wang S. Paclitaxel/gelatin coated magnetic mesoporous silica nanoparticles: Preparation and antitumor efficacy in vivo. Microporous and Mesoporous Materials. 2015; 204: 226-234.

\section{Pawar AP, Vinugala D, Bothiraja C.} Nanocochleates derived from nanoliposomes for paclitaxel oral use: Preparation, characterization, in vivo anticancer testing, bioavailability and biodistribution study in rats. Biomedicine and Pharmacotherapy. 2014 in press.

Pezzuto JM. Plant- Derived Anticancer Agents. Biochemical Pharmacology. 1997;53:121-133.

Cragg GM, Newman DJ. Plants as a source of anti-cancer agents. Journal of Enthnopharmacology. 2005;100: 72-79.

Unnati S, Ripal S, Sanjeev A, Niyati A. Novel anticancer agents from plant sources. Chinese Journal of Natural Medicines. 2013;11(1):0016-0023.

Solowey E, Lichtenstein M, Sallo S, Paavilainen $H$, Solowet $E$, LorberboumGalski H. Evaluating Medicinal Plants for Anticancer Activity. The Scientific World Journal . 2014:2014:1-12.

Risinger AL, Giles FJ, Mooberry SL. Microtubule dynamics as a target in oncology. Cancer Treatment Reviews. 2009:35:255-261.

Son IH, Chung IM, Lee SI, Yang HD, Moon HI. Pomiferin, histone deacetylase inhibitor isolated from the fruits of Maclura pomifera. Bioorganic \& Medicinal Chemistry Letters. 2007;17:4753-4755.

Hakim IA, Harris RB, Brown S, Chow HHS, Wiseman S, Agarwal S, Talbot W. Effect of Increased Tea Consumption on Oxidative DNA Damage among Smokers: A Randomized Controlled Study. The Journal of Nutrition. 2003;133(10):33035$3309 S$.

Raza H, John A. Green tea polyphenol epigallocatechin-3-gallate differentially modulates oxidative stress in PC12 cell 2020 September Edition | www.jbino.com | Innovative Association 
compartments. Toxicology and Applied Pharmacology. 2005;207:212-220.

Newcomb EW. Flavopiridol: pleiotropic biological effects enhance its anti-cancer actvity. Anti-Cancer Drugs. 2004;15(5):411-419.

Jyoti K, Kaur K, Pandey RS, Jain UK, Chandra R, Madan J. Inhalable nanostructured lipid particles of 9-bromonoscapine, a tubulin-binding cytotoxic agent: In vitro and in vivo studies. Journal of Colloid and Interface Science. 2015;445: 219-230.

Henary M, Narayana L, Ahad S, Gundala SR, Mukkavilli R, sharma V, Owens EA, Yadav $Y$, Nagaraju $M$, Hamelberg $D$, Tandon V, Panda D, Aneja R. Novel thirdgeneration water-soluble noscapine analogs as superior microtubuleinterfering agents with enhanced antiproliferative activity. Biochemical Pharmacology. 2014; 92:192-205.

Chen X, Dang TT, Facchini PJ. Noscapine comes of age. Phytochemistry. 2015;111:7-13.

Amos LA, Löwe J. How Taxolß stabilises microtubule structure. Chemistry \& Biology. 1999;6(3):65-69.

Khazir J, Mir BA, Pilcher L, Riley DL. Role of plants in anticancer drug discovery. Phytochemistry Letters. 2014; 7:173-181.

Bhatnagar P, Pant AB, Shukla Y,
Chaudhari B, Kumar P, Gupta KC. Bromelain nanoparticles protect against 7,12-dimethylbenz[a] anthracene induced skin carcinogenesis in mouse model. European Journal of
Pharmaceutics and Biopharmaceutics. 2015; 91:35-46.

Balasubramani G, Ramkumar R, Krishnaveni N, Pazhanimuthu A, Natarajan T, Sowmiya R, Perumal P. Structural characterization, antioxidant and anticancer properties of gold nanoparticles synthesized from leaf extract (decoction) of Antigonon leptopus Hook. \& Arn. Journal of Trace Elements in Medicine and Biology. 2015;30: 83-89.

Kumar SR, Priyatharshni S, Babu VN, Mangalaraj D, Viswanathan C, Kannan S, Ponpandian N. Quercetin conjugated superparamagnetic magnetite nanoparticles for in-vitro analysis of breast cnacer cell line for chemotherapy applications. Journal of Colloid and Interface Science. 2014;436:234-242.

Zschocke S, Rabe T, Taylor JLS, Jäger AK, van Staden J. Plant part substitution - a way to conserve endangered medicinal plants? Journal of Ethnopharmacology. 2000; 71:281-292.

Parveen S, Jan U, Kamili A. Importance of Himalayan medicinal plants and their conservation strategies. Australian Journal of Herbal Medicine. 2013; 25 $(2): 63-67$.

Kasagana VN, Karumuri SS. Conservation of Medicinal Plants (Past, Present \& Future Trends) Journal of Pharmaceutical Sciences and Research. 2011 ; 3(8):13781386.

Stagos D, Amoutzias GD, Matakos A, Spyrou A, Tsatsakis AM, Kouretas D. Chemoprevention of liver cancer by 
plant polyphenols. Food and Chemical Toxicology. 2012 ; 50:2155-2170.

Sahpazidou D, Geromichalos GD, Stagos D, Apostolou A, Haroutouian SA, Tsarsakis AM, Tzanakakis NG, Hayes AW, Kouretas

D. Anticarcinogenic activity of polyphenolic extracts from grape stems against breast, colon, renal and thyroid cancer cells. Toxicology Letters. 2014; $230: 218-224$.

World Health Organisation . The World Health Organisation's Fight Against Cancer: Strategies that prevent, cure and care. WHO Press; Geneva: 2007.

Jemal A, Siegel R, XU J, Ward E. Cancer Statistics, 2010. CA: A Cancer Journal for Clinicians. $2010 ; 60$ : 277-300.

Cancer Research UK [Accessed 23 January 2015]; World cancer statistics. 2014 Available at: http://www.cancerresearchuk.org/canc er-info/cancerstats/world/ 